\title{
PATRIMÔNIO E EDUCAÇÃO
}

CONTRIBUIÇÕES DA REDE PAULISTA DE EDUCAÇÃO PATRIMONIAL PARA O TEMA

JOÃO LORANDI DEMARCHI

Universidade de São Paulo, São Paulo, São Paulo, Brasil

DOI

http://dx.doi.org/10.11606/issn.1980-4466.v0i20p207-215
RECEBIDO

$19 / 08 / 2015$

APROVADO

$23 / 11 / 2015$ 


\section{INTRODUÇÃO}

Para o início desta leitura é importante ressaltar alguns pressupostos. O autor deste depoimento é integrante da Rede Paulista de Educação Patrimonial (Repep), no entanto, ele não produziu este texto como porta-voz da Repep. No decorrer destas páginas apresentaremos visões particulares, a partir de nosso lugar, sobre a própria Repep. Trata-se de uma pessoa analisando o grupo no qual está imerso. Cada ponto de vista é "a vista de um ponto", portanto não detemos uma visão total e imparcial do objeto tratado, o que implica ser este recorte selecionado para abordarmos aqui a escolha de um integrante da Repep.

Este texto pretende apresentar a Repep. Para tanto, será necessário explorar a problemática que ensejou a criação dela: a conjuntura da educação patrimonial brasileira. Também trataremos da trajetória histórica da Repep, tendo seu início dentro da Universidade de São Paulo; qual é o método de atuação hoje em dia; e atentaremos para os desafios do funcionamento em rede. Destacaremos os marcos da Repep, que avaliamos serem contribuições importantes para o avanço da discussão sobre a educação patrimonial. Por fim, indicaremos algumas perspectivas de atuação que vislumbramos para a Repep no tema educação patrimonial. 


\section{A EDUCAÇÃO PATRIMONIAL, UM CAMPO DE ESTUDO}

A educação patrimonial é um campo que foi tratado enquanto esfera de atuação administrativa pelo Instituto do Patrimônio Histórico e Artístico Nacional (Iphan) só recentemente. A criação da Coordenação de Educação Patrimonial (Ceduc) foi no ano de 2000. A Gerência de Educação Patrimonial e Projetos (Geduc), é mais recente, foi criada em 2004. Porém, a educação com foco no patrimônio é abordada há mais tempo. No famoso anteprojeto de Mário de Andrade, de 1936, para a criação do Serviço do Patrimônio Histórico e Artístico Nacional (Sphan) já havia menção à importância do caráter pedagógico dos museus e a importância da educação para a preservação do patrimônio, como escreve Florêncio et al. (2014). Essa concepção também foi aderida por pessoas importantes para a consolidação do campo patrimonial no Brasil, como Rodrigo Melo Franco de Andrade (1898-1969) e Aloísio Magalhães (1927-1982).

Apesar disso, como aponta Oliveira (2011), a educação patrimonial ainda é vista hoje em dia como acessória à preservação do patrimônio cultural. Está quase sempre relegada à última etapa da patrimonialização, como as ações de promoção de tombamentos. Quando assim, a educação patrimonial volta-se à mera divulgação de informações e gera uma confusão comum que também é descrita pela autora: a confusão entre ação educativa, ação de capacitação e ação de divulgação. Uma ação educativa pode ter um componente de divulgação, mas não deve ser confundida com esta. Portanto, a educação patrimonial deve se constituir em ações que pressuponham uma intervenção específica com o propósito de que o indivíduo se aproprie dos bens culturais e os preserve. Ela deve dispor de várias metodologias para atingir seus propósitos, ao contrário da proposta do Guia básico de educação patrimonial (HORTA et al., 1999) de a educação patrimonial ser uma metodologia específica.

Esse guia foi um importante documento para o campo da educação patrimonial no Brasil, editado pelo Iphan. Até hoje é utilizado por muitos proponentes de ações educativas como referencial teórico-metodológico. Mas, como lembra Scifoni (2012), todo conhecimento é historicamente datado e as práticas de educação patrimonial há tempos necessitam de avanços teóricos.

Para além dessa crítica, Chagas (2006) aponta que as práticas educativas em museus - portanto atividades de educação com foco no patrimônio - já 
ocorriam no Brasil no século XIX. Dessa forma, a tentativa, corroborada pelo guia, de forjar um "marco zero" para a educação patrimonial, tendo o $1^{\circ}$ Seminário Uso Educacional de Museus e Monumentos no Museu Imperial, realizado em Petrópolis em 1983, não condiz com a realidade prática dos proponentes de atividades e programas de educação patrimonial.

Somado a esse panorama atual da educação patrimonial no Brasil, encontra-se uma incipiente discussão acadêmica que não fornece avanços significativos de proposições teórico-metodológicas para as infinitas ações espalhadas pelos municípios. As pesquisas disponíveis sobre o tema concentram-se, sobretudo, no programa de mestrado profissional do Iphan, o Programa de Especialização em Patrimônio (PEP). No entanto, das aproximadamente 80 dissertações defendidas entre 2012 e 2014, apenas quatro (5\%) abordam o tema educação patrimonial.

Também não há um esforço em sistematizar as ações existentes a fim de analisá-las. Ou melhor, não havia. É a partir daqui que falamos da Repep.

\section{A REPEP: A TRAJETÓRIA}

Em 2011, a Profa. Dra. Simone Scifoni cadastrou o projeto "Educação patrimonial na USP: mapeamento e conceituação" no programa "Aprender com cultura e extensão" da Pró-Reitoria de Cultura e Extensão Universitária da USP (PRCEU-USP). Este projeto visava organizar a Rede Estadual Paulista de Educação Patrimonial, e foi estruturado de forma articulada às propostas de trabalho desenvolvidas no Centro de Preservação Cultural, configurando-se como uma iniciativa em parceria entre o Laboratório de Geografia Urbana (Labur), do Departamento de Geografia da USP, e o Centro de Preservação Cultural da USP (CPC-USP). Nesta ocasião, foram concedidas bolsas para dois monitores. Era objetivo do projeto formar um banco de dados que levantasse informações sobre as ações educativas com foco no patrimônio cultural que foram ou estavam sendo desenvolvidas em território paulista, bem como mapeá-las. Desde então, a preocupação era refletir sobre os princípios e a fundamentação teórica-conceitual da educação patrimonial. $\mathrm{O}$ fomento da USP durou um ano. Em 2012 foram novamente concedidas as bolsas, naquele momento para a Fase 2 do projeto: foi criado o site da Rede (http://www. repep.fflch.usp.br), importante plataforma na qual está disponível o banco 
de dados da Repep com os projetos de ação educativa cadastrados, contatos de profissionais que desenvolvem ações de educação patrimonial, bem como outros dispositivos da Repep (boletins, calendário, informações dos grupos de trabalho e bibliografia sobre a temática). É notável a projeção externa à Universidade desde o início das atividades, um trabalho voltado para a sociedade. Neste mesmo ano, durante o Simpósio do Programa Aprender com Cultura, patrocinado pela PRECEU-USP, o projeto recebeu menção honrosa, destacando-se na categoria Ciências Humanas.

Mais um ano se passou e foi preciso repetir o processo de solicitação de bolsas para os monitores, fundamentais para a viabilização do projeto. Em 2013, o projeto de pesquisa foi intitulado Rede Paulista de Educação Patrimonial. Neste momento, houve uma virada significativa na Rede. A primeira reunião daquele ano de vigência da bolsa, em julho de 2013, foi realizada em Santos, na base avançada da USP Ruínas Engenho São Jorge dos Erasmos. Para além dos dois monitores-bolsistas e da professora coordenadora, na reunião houve a participação de professores da rede pública, mestrandos e arquitetos. Foram traçados alguns encaminhamentos para as próximas reuniões, que desde então passaram a acontecer no Centro de Preservação Cultural da USP (CPC-USP). Nessas reuniões, abertas a todos interessados no assunto, discutem-se textos que abordam a educação e os integrantes relatam suas experiências vividas. Com o passar do tempo, mais pessoas aderiram à causa da Rede e mais a discussão avançou. Sob esse contexto que foi escrito o documento "Princípios da Educação Patrimonial". Trata-se de um conjunto de seis princípios que os integrantes da Repep elaboraram conjuntamente a fim de que sirva de subsídio para as ações, projetos e programas educativos que visem o patrimônio cultural. Em maio de 2014 promoveu-se o I Encontro de Trabalho da Repep no Centro Universitário Senac - Santo Amaro, que contou com a participação de aproximadamente 70 pessoas. Nesse evento, na parte da manhã, ocorreu uma mesa composta por Sônia Florêncio, do Iphan-Brasília; Nádia Somekh, do Conpresp e Departamento do Patrimônio Histórico; Alberto Bertagna, do Iphan-São Paulo; e Gabriel Fernandes, da Repep. Na parte da tarde, todos os participantes do Encontro se dividiram em grupos de trabalho e debruçaram-se sobre três questões: "O que deve ser a Repep?", "Como fazer acontecer?" e "Como posso contribuir?" Esse Encontro deu origem à Carta 
da Repep, documento que sistematizou as discussões levantadas naquele dia.

Novamente, o ano da concessão da bolsa aos monitores-bolsistas é finalizado. Agora com um ritmo maior, reuniões periódicas consolidadas, contando com a participação voluntária de diversos profissionais da sociedade e uma projeção grande. Desta vez a Repep perde uma das duas bolsas que detinha devido à crise orçamentária da Universidade de São Paulo, que cortou diversas bolsas.

Assim, o quarto ano da Repep, iniciado em julho de 2014, começou com trabalho dobrado e monitores pela metade, apenas um. Neste momento, o site da Repep se consolidou como uma ferramenta fundamental de comunicação, ao lado da newsletter que divulga os eventos internos e externos à Repep, e da página no Facebook, que é uma alternativa de contato; plataformas que veiculam também os boletins periódicos desenvolvidos pela Repep. Essas são algumas das tarefas desempenhas pelo monitor.

Com o tempo há saída e entrada de integrantes. Surgiram demandas. Em Fóruns e Seminários a Repep é apresentada, ora por seus próprios integrantes, ora por pessoas que conhecem o trabalho da Rede. Assim o trabalho vai avançando até que se chega ao momento atual, em que o trabalho é dividido em Grupos de Trabalho.

\section{MÉTODO}

O único subsídio que a Repep recebe provém da Pró-Reitoria de Cultura e Extensão Universitária da USP, que concede uma bolsa de R $\$ 400,00$ a um aluno de graduação da própria universidade, cadastrado no Programa de Apoio à Permanência Estudantil; essa bolsa possui, portanto, um caráter de assistência social. O bolsista, no caso da Repep, exerce algumas funções como, por exemplo, participar das reuniões e redigir suas memórias; administra o site, o e-mail e a página no Facebook, na qual divulga eventos sobre educação patrimonial, veicula os boletins da Repep que são diagramados por ele e divulga as reuniões da Rede. $\mathrm{O}$ monitor participa das discussões teórico-conceituais e pode participar de algum Grupo de Trabalho que preferir.

Os Grupos de Trabalho contam com a participação voluntária de pessoas da sociedade que compõem a Repep e se engajem, movidos pela identificação por determinado tema. Destaca-se, por exemplo, o GT Minhocão, que trata do levantamento participativo das referências culturais no entorno do Elevado Costa e Silva, na região central de São Paulo, e estuda o possível 
impacto da criação do Parque do Minhocão. Há ainda o GT Brasilândia, que começou suas atividades a partir de uma demanda proposta por moradores do bairro. A intenção inicial era se debruçar sobre a Matriz da Freguesia do Ó, um patrimônio que estava sendo comprometido pela construção de prédios que obstruem a visão do seu edifício.

A Rede Paulista de Educação Patrimonial não é prestadora de serviço e não se vincula diretamente a nenhuma instituição. Não tem fins lucrativos. Este coletivo é uma rede aberta à participação de qualquer interessado na temática, tem suas decisões tomadas de forma coletiva, sem hierarquias. $\mathrm{O}$ que existe são mediadores que tomam a liderança de forma circunstancial. Há documentos que norteiam o trabalho e estabelecem balizas de atuação: "Princípios da Educação Patrimonial", "Carta da Repep" e "Estatuto da Repep", que são formas de organização do trabalho em rede, uma forma democrática e acessível de atuação.

Desta forma, pretende-se a construção coletiva do estudo, da pesquisa e da proposição de soluções. A pessoa ou o grupo que faz a demanda busca a solução para um problema, mas o que encontra não é uma resposta assertiva e sim pessoas que se dispõem a trabalhar conjuntamente, contribuindo conforme podem. Pode-se dizer tratar de uma "meta-educação patrimonial": a Repep faz dos seus princípios de educação patrimonial seu próprio método de atuação. Explico. A educação patrimonial, na concepção da Repep, parte, dentre outros princípios, de ser um processo dialógico e transversal com respeito à diversidade, ou seja, promove-se a participação ativa da comunidade envolvida e está presente em todas as etapas da patrimonialização (do reconhecimento à preservação) considerando a diversidade de narrativas sobre determinado objeto e seus inúmeros significados.

\section{CONTRIBUIÇÕES}

Considerou-se a necessidade de avanços teóricos-conceituais quando se pensou a criação da Repep. Ao longo do tempo, atuando em diversas frentes, o foco sempre foi a promoção da discussão sobre educação patrimonial a fim de que se adense o debate, ensejando mais pensadores sobre o tema e, também, a proposição de novas ideias e formas de se pensar ações educativas com foco no patrimônio.

Desta forma, alguns marcos da história da Repep constituem 
consideráveis contribuições para a educação patrimonial, sobretudo a paulista.

Primeiro, o próprio esforço inicial de mapear as práticas e sistematizá-las em um banco de dados. Os documentos que foram escritos também são importantes para o debate. Há, na sequência cronológica, os "Princípios da Educação Patrimonial”, um documento que sugere seis princípios norteadores para qualquer prática educativa; e a "Carta da Repep", texto que sistematiza questões levantadas no I Encontro de Trabalho da Repep.

Outro fator consideravelmente eficaz, e igualmente enriquecedor, é a forma de atuação em grupos de trabalhos. Para além dos muros da Universidade, embora forme com ela um conjunto, a Repep trabalha a partir da sociedade, com a sociedade e para a sociedade.

\section{PERSPECTIVAS}

Levando em consideração que a Repep conta com o apoio financeiro para apenas um monitor, o trabalho desenvolvido pelos voluntários que a compõem torna-se mais grandioso. Muitas contribuições ao debate foram feitas, mas muitas há ainda por vir. O conhecimento e o trabalho devem avançar.

Para tanto, vislumbra-se a criação de um laboratório de educação patrimonial: consistirá em um espaço físico onde se possa armazenar o acervo da Repep, bem como uma infraestrutura que forneça mesas para a realização de reuniões, computadores para a viabilização de atividades e o financiamento para a contratação de um técnico que organize esta estrutura. Dessa forma, os encontros são realizados no CPC-USP ou no Iphan-SP, espaços cedidos de forma generosa, e o acervo atualmente guardado encontrarão um lugar ideal para seu melhor aproveitamento: o acervo poderá ser consultado por qualquer interessado e o espaço ensejará o encontro de pessoas envolvidas na temática. Assim, o avanço do debate será potencializado, envolvendo acadêmicos ou não.

Pensa-se que com o avançar do tempo, novas contribuições serão realizadas e mais pessoas irão aderir à Repep, mas, além disso, maior será o número de pessoas que pensam a educação patrimonial. Pois é preciso que mais pessoas encarem a educação patrimonial não só como um campo de atuação, mas também como um objeto de pesquisa. Um objeto que deve ser abordado. 


\section{CONCLUSÃO}

A Repep nasceu da identificação de um campo de atuação que está, ainda hoje, pouco ocupado e sobre ele existe uma discussão incipiente. A partir de então, passaram alguns anos e algumas contribuições foram feitas. A sistematização do banco de dados de projetos de ações educativas, disponível no site, expôs, sem discriminação, os proponentes. Intentou-se com isso projetar as ações para além de suas localidades e fornecer material referencial para quem se interessar. Com isto, a Repep é, sobretudo, uma importante plataforma para debates que deve ser preservada. É preciso fortalecer a existência da Repep com maior fomento por parte das agências de pesquisa, e pela própria Universidade de São Paulo. É preciso (re) conhecimento, por parte da sociedade, da atuação deste coletivo. Enquanto isso, a Repep segue fazendo seu trabalho.

\section{REFERÊNCIAS}

CHAGAS, Mário. Educação, museu e patrimônio: tensão, devoração e adjetivação. Dossiê Educação Patrimonial, n. 3, Iphan, jan./fev. 2006.

FLORÊNCIO, Sônia R. R. et al. Educação patrimonial: histórico, conceitos e processos. Brasília, DF: Iphan, 2014.

HORTA, Maria de Lourdes P.; GRUMBERG, Evelina; MONTEIRO, Adriane Q. Guia básico de educação patrimonial. Brasília: Iphan, Museu Imperial, 1999.

OLIVEIRA, Cléo Alves P. Educação patrimonial no Iphan. Monografia de Especialização. Escola Nacional de Administração Pública, Brasília, DF, 2011.

SCIFONI, Simone. Educação e patrimônio cultural: reflexões sobre o tema. In: TOLENTINO, Atila B. Educação patrimonial: reflexões e práticas. João Pessoa: Superintendência do Iphan-PB, 2012.

\section{SITES}

http://www.repep.fflch.usp.br 